\title{
Rate of complications due to neuromuscular scoliosis spine surgery in a 30-years consecutive series
}

\author{
Francesco Turturro $^{1}$ - Antonello Montanaro ${ }^{1} \cdot$ Cosma Calderaro $^{1}{ }^{1}$ - \\ Luca Labianca $^{1} \cdot$ Vincenzo Di Sanzo $^{1} \cdot$ Andrea Ferretti $^{1}$
}

Received: 12 February 2017/Revised: 6 March 2017 / Accepted: 8 March 2017

(C) Springer-Verlag Berlin Heidelberg 2017

\begin{abstract}
Purpose The aim of this study was to evaluate the rate of intraoperative and postoperative complications in a large series of patients affected by neuromuscular scoliosis.

Methods It was a monocentric retrospective study. In this study have been considered complications those events that significantly affected the course of treatment, such as getting the hospital stay longer, or requiring a subsequent surgical procedure, or corrupting the final result of the treatment.

Results Of the 358 patients affected by neuromuscular scoliosis treated from January 1985 to December 2010, 185 that met the inclusion criteria were included in the study. There were recorded 66 complications in 55/185 patients. Of that 66 complications, 54 complications occurred in 46/120 patients with Luque's instrumentation, while only 12 complications occurred in 9/65 patients with hybrid instrumentation and this difference was statistically significant $(p<0.05) ; 11 / 126$ patients with pelvic fixation and $5 / 59$ without pelvic fixation, as well as 45/156 patients treated by posterior approach alone and 10/29 patient that underwent combined anterior-posterior approach suffered complications but both this did not result in a statistical significant difference $(p>0.05)$.

Conclusions The surgical treatment in neuromuscular scoliosis is burdened by a large number of complications. An accurate knowledge of possible complications is
\end{abstract}

Cosma Calderaro

cosma.calderaro@gmail.com

1 Department of Orthopaedic and Traumatology, S. Andrea Hospital, Faculty of Medicine and Psychology, "Sapienza" University of Rome, Via di Grottarossa, 1035, 00189 Rome, Italy mandatory to prepare strategies due to prevent adverse events. A difference in definitions could completely change results in good or bad as well as in our same series the adverse events amounted at almost $30 \%$ of cases, but complications that due to complete failure would amount at $9.19 \%$ of patients.

Keywords Scoliosis - Neuromuscular scoliosis . Complications $\cdot$ Scoliosis surgery

\section{Introduction}

Patients with neuromuscular diseases frequently develop scoliosis that requires surgical correction [1-10]. Usually the deformity involves the entire thoracic and lumbar spine resulting in a $\mathrm{C}$-shaped curve often associated with great pelvic obliquity. Spine fusion in neuromuscular scoliosis aims to balance the trunk in frontal and sagittal plane, center the head over the pelvis, and restore anatomical spine condition. Extension into the pelvis is meant to achieve global correction of both pelvic and spinal deformity.

Patients with neuromuscular scoliosis undergoing posterior spinal fusion are at higher risk for postoperative complications due to underlying comorbidities [11-14] such as decreased pulmonary function, inadequate nutritional status, decreased mobility, costo-pelvic impingement pain and cognitive impairment. Complication rate associated with spinal surgery in neuromuscular scoliosis ranges from 18 to $75 \%$ [15-27].

The aim of this study was to evaluate the rate of intraoperative and postoperative complications in a large series of patients affected by neuromuscular scoliosis and to determine if the rate of complications varies in different 
neuromuscular diseases and in the two different surgical instrumentations (Luque, older, and Hybrid, newer) used.

\section{Materials and methods}

It was a monocentric retrospective study. Between January 1985 and December 2015, 358 consecutive patients operated on for scoliosis by the same operators (senior authors F.T. and A.M.) were reviewed. Inclusion criteria were: diagnosis of neuromuscular scoliosis, all procedures consecutively performed, appropriate documentation by clinical records, minimum follow-up of 5 years. Demographic data, type of neuromuscular disease, age at surgery, surgical approach, pelvic fixation, instrumentation used and complications have been collected.

Indication for spinal surgery was a scoliosis greater than 40 degrees, when associated with pelvic imbalance affecting a comfortable sitting in the wheelchair and limiting the caregivers' actions, fixation has been extended to the pelvis.

Fusion was achieved by local bone graft mixed with synthetic bone after thorough decortications of laminae. The preoperative antibiotic prophylaxis was $50 \mathrm{mg} / \mathrm{kg}$ of cefazolin and $15 \mathrm{mg} / \mathrm{kg}$ of amikacin, continued postoperatively since the central venous catheter removal.

After surgery the patients were transferred to the intensive care unit (still intubated if necessary) for a minimum time of $48 \mathrm{~h}$, and discharged to the orthopaedic unit when stable.

In this study have been considered complications those events that significantly affected the course of treatment, such as getting the hospital stay longer, or requiring a subsequent surgical procedure, or corrupting the final result of the treatment.

For statistical analysis, Student's $t$ test was used. Data are presented as mean values and range. For continuous parameters, when the distribution was not normal, a MannWhitney nonparametric test was used. Results were considered statistically significant when value was less than 0.05 .

\section{Results}

Of the 358 patients affected by neuromuscular scoliosis treated from January 1985 to December 2010, 185 that met the inclusion criteria were included in the study. According to the definition of complication, we have excluded six cases of failure of the instruments (two broken rods, one overhang rod, and three loops derailment) that did not result in loss of correction or patient discomfort and the transient paresthesia in the innervation area of the lateral femoral cutaneous nerve. There were included 86 males $(46.49 \%)$ and 99 females $(53.51 \%)$, mean age at surgery was 13.62 years (range 6-34 years) and mean follow-up was 10.7 years (range 5-25 years).

The stratification of patients was (Table 1): $51(27.57 \%)$ cerebral palsy (CP), $48(25.95 \%)$ muscular dystrophy (MD), 31 (16.76\%) spinal muscular atrophy (SMA) including 26 SMA Type II and 5 SMA Type III, 15 (8.12\%) Rett syndrome (RS), $12(6.47 \%)$ poliomyelitis and medullar damages (PMD), 28 (15.14\%) others neuromuscular disorders (Friedreich ataxia, Lennox-Gastaut disease, Aicardi syndrome, genetic syndromes, neuropathies).

One hundred and twenty $(64.86 \%)$ patients underwent posterior arthrodesis using the Luque's instrumentation, 65 $(35.14 \%)$ patients underwent posterior arthrodesis using hybrid instrumentation. Twenty-nine (15.68\%) patients underwent anterior and posterior arthrodesis, 26 by a thoracotomy approach and three by a video-assisted thoracoscopy. One hundred and twenty-six (68.11\%) patients underwent a modified trans-iliac pelvic fixation (Table 2).

There were recorded 66 complications in 55/185 (29.73\%) patients (Table 1).

According the Rampersaud's Spine Adverse Event Severity System (SAVES) [28] the complications recorded can by graded as follow (Table 1): 16 complications grade I (10 ileus paralyticus and 6 mechanical complications); 9 complications grade II (3 delayed wound healing, 2 SIADH, 2 decubitus, 1 peptic ulcer, 1 heterotopic ossification of the gluteus); 39 complications grade III (9 mechanical complications, 16 infections, 3 neurological complications, 2 crankshaft phenomenon [22]); 2 complications grade IV (2 deaths).

Of that 66 complications, 54 complications occurred in $46 / 120(38.33 \%)$ patients with Luque's instrumentation, while only 12 complications occurred in 9/65 (13.85\%) patients with hybrid instrumentation and this difference was statistically significant $(p=0.0005) ; 11 / 126$ patients $(8.73 \%)$ with pelvic fixation and $5 / 59$ without pelvic fixation, as well as $45 / 156(28.85 \%)$ patients treated by posterior approach alone and 10/29 (34.48\%) patients that underwent combined anterior-posterior approach suffered complications but both this did not result in a statistical significant difference ( $p=0.95$ and $p=0.54$ ) (Table 2).

According to the neuromuscular disease, 21 complications were observed in 18 patients with $\mathrm{CP}, 14$ complications in 13 patients with MD, 15 complications in ten patients with SMA, 6 complications in five patients with RS, 6 complications in six patients with PMD, 4 complications in three patients with other neuromuscular diseases (Table 1).

Mechanical complications were 15 in 16 (8.65\%) patients; they included breaks, shifts and decubiti of the instrumentation and a case (without pelvic fixation) of 
Table 1 Complications recorded

\begin{tabular}{|c|c|c|c|c|c|c|c|c|c|}
\hline Complications & $\begin{array}{l}\text { SAVES } \\
\text { grade }\end{array}$ & $\begin{array}{l}\text { Number of } \\
\text { complication }\end{array}$ & $\begin{array}{l}\text { Percentage in } \\
\text { total patients }\end{array}$ & $\mathrm{CP}$ & MD & SMA & RS & PMD & Others \\
\hline Infection & III & $16(24.24 \%)$ & $8.65 \%$ & $5(23.81 \%)$ & $5(35.71 \%)$ & $2(13.33 \%)$ & $2(33.33 \%)$ & $1(16.67 \%)$ & $1(25.00 \%)$ \\
\hline Mechanical & $\begin{array}{l}\text { I (6) III } \\
\text { (9) }\end{array}$ & $15(22.73 \%)$ & $8.65 \%$ & $5(23.81 \%)$ & $1(7.14 \%)$ & $5(33.33 \%)$ & $2(33.33 \%)$ & - & $2(50.00 \%)$ \\
\hline Ileus & I & $10(15.15 \%)$ & $5.41 \%$ & $4(19.05 \%)$ & $2(14.29 \%)$ & $2(13.33 \%)$ & - & $2(33.33 \%)$ & - \\
\hline Respiratory & III & $9(13.64 \%)$ & $4.86 \%$ & $3(14.29 \%)$ & $1(7.14 \%)$ & $3(20.00 \%)$ & $2(33.33 \%)$ & - & - \\
\hline $\begin{array}{l}\text { Delayed wound } \\
\text { healing }\end{array}$ & II & $3(4.55 \%)$ & $1.62 \%$ & - & $1(7.14 \%)$ & $1(6.67 \%)$ & - & $1(16.67 \%)$ & - \\
\hline Neurological & III & $3(4.55 \%)$ & $1.62 \%$ & $2(9.52 \%)$ & - & - & - & $1(16.67 \%)$ & - \\
\hline SIADH & II & $2(3.03 \%)$ & $1.08 \%$ & - & $1(7.14 \%)$ & - & - & $116.67 \%)$ & - \\
\hline Crankshaft & III & $2(3.03 \%)$ & $1.08 \%$ & - & - & $1(6.67 \%)$ & - & - & $1(25.00 \%)$ \\
\hline Death & IV & $2(3.03 \%)$ & $1.08 \%$ & - & $1(7.14 \%)$ & $1(6.67 \%)$ & - & - & - \\
\hline Decubitus & II & $2(3.03 \%)$ & $1.08 \%$ & $2(9.52 \%)$ & - & - & - & - & - \\
\hline Peptic Ulcer & II & $1(1.52 \%)$ & $0.54 \%$ & - & $1(7.14 \%)$ & - & - & - & - \\
\hline HPO of the gluteus & II & $1(1.52 \%)$ & $0.54 \%$ & - & $1(7.14 \%)$ & - & - & - & - \\
\hline Total complications & - & 66 & - & 21 & 14 & 15 & 6 & 6 & 4 \\
\hline $\begin{array}{l}\text { Patients with } \\
\text { complications }\end{array}$ & - & $\begin{array}{l}55 / 185 \\
\quad(29.73 \%)\end{array}$ & - & $\begin{array}{l}18 / 51 \\
(35.29 \%)\end{array}$ & $\begin{array}{l}13 / 48 \\
(27.08 \%)\end{array}$ & $\begin{array}{l}10 / 31 \\
(32.25 \%)\end{array}$ & $\begin{array}{l}5 / 15 \\
(33.33 \%)\end{array}$ & $\begin{array}{l}6 / 12 \\
\quad(50.00 \%)\end{array}$ & $\begin{array}{l}3 / 28 \\
\quad(10.71)\end{array}$ \\
\hline
\end{tabular}

SAVES Spine AdVerse Event Severity system, SIADH Syndrome of Inappropriate AntiDiuretic Hormone secretion, HPO Heterotopic Painful Ossification

Table 2 Complication in different surgical technique

\begin{tabular}{lccrc}
\hline Surgical technique & No patients & Patients with complications & $\%$ & $p$ \\
\hline Luque & 120 & 46 & 38.33 & $\mathbf{0 . 0 0 0 5}$ \\
Hybrid & 65 & 9 & 13.85 & \\
Pelvic fixation & 126 & 11 & 8.73 & 0.95 \\
No Pelvic fixation & 59 & 5 & 8.47 & \\
Posterior approach & 156 & 45 & 28.85 & 0.54 \\
Anterior + posterior approach & 29 & 10 & 34.48 & \\
\hline
\end{tabular}

Bold value denotes statistical significance $(p<0.05)$

\begin{tabular}{llcrrr}
\hline Complication & Instrumentation & Patients & No complications & $\%$ & $p$ \\
\hline \multirow{2}{*}{ Mechanical } & Luque & 120 & 15 & 12.50 & $\mathbf{0 . 0 1}$ \\
& Hybrid & 65 & 1 & 1.54 & \\
\multirow{3}{*}{ Infection } & Luque & 120 & 10 & 8.33 & 0.84 \\
\multirow{3}{*}{ Respiratory } & Hybrid & 65 & 6 & 9.23 & \\
\multirow{3}{*}{ Ileus } & Luque & 120 & 7 & 5.83 & 0.41 \\
& Hybrid & 65 & 2 & 3.08 & \\
& Luque & 120 & 10 & 8.33 & $\mathbf{0 . 0 2}$ \\
& Hybrid & 65 & 0 & 0 & \\
\hline
\end{tabular}

Bold values denote statistical significance $(p<0.05)$

recurrence of the pelvic obliquity (Table 3 ). These required 11 surgical procedures (4 rod resections, 3 instrument removals of and 4 revisions). In four cases a second surgery was not performed because in two patients the general health contraindicated a new procedure and in other two patients the parents refused.

There were recorded 16 wound infections in 16 patients $(8.65 \%)$, nine early infections (in the first postoperative month) and seven late infections (more than 1 year after surgery) (Table 3). Fifth-teen of these patients underwent the wound debridement and in nine patients it was necessary the removal of the instrumentation.

Respiratory complications were nine (4.86\%), six pneumonias/bronchopneumonia and three respiratory failures that need a permanent tracheostomy in two patients and a temporary tracheostomy in one patient (Table 3). 
There were recorded ten transient ileus in ten $(5.41 \%)$ patients (Table 1).

Less common were 3 delayed wound healing in three patients $(1.62 \%) ; 3$ neurological complication in three $(1.62 \%)$ patients (2 paraplegia in patients with $\mathrm{CP}$ and 1 neurogenic bladder in a patient with poliomyelitis); 2 syndrome of inappropriate antidiuretic hormone secretion (SIADH) in two (1.08\%) patients; 2 crankshaft phenomenon in two $(1.08 \%)$ patients, 1 with SMA II and 1 affected by Aicardi syndrome, both operated at the age of 9 years by the posterior approach alone (in the second case, the breakdown of rods led to a revision surgery to repair the damage, correcting loss of correction); two (1.08\%) perioperative deaths, one female patient affected by congenital muscular dystrophy that leaved during the second postoperative day because a fatal cardiac arrhythmia and in one female affected by SMA II because an aeroembolism during the wound debridement for the treatment of an early infection; two (1.08\%) patients suffered of a decubitus, both treated with vacuum therapy, one $(0.54 \%)$ suffered of peptic ulcer and one (0.54\%) suffered of a painful heterotopic ossification of the gluteus (Table 1).

\section{Discussion}

This study has been conducted to help surgeons in predicting and managing possible complications in neuromuscular patients undergoing scoliosis surgery. It certainly shows some limitations as to be a retrospective study and to not report surgery time and blood loss, due to the not guarantee about data accuracy in the oldest paperwork. On the other hand, there are some strong points that add value as the mono-équipe procedure along 30 years, the accuracy in definition of complications, the long term follow-up, the wide size of the study group that allows an intergroup comparison, so that for the first time has been shown possible differences among most known neuromuscular diseases (CP, DMD, SMA, RETT).

The surgical treatment of neuromuscular scoliosis has a high rate of complications. The prevalence of the complications of the surgical treatment ranges from 18 to $75 \%$ [23-38].

Adverse events, called complications, are classified in different ways among the literature. One common criterion is time, so to have intraoperative, early and late postoperative. Another one is major and minor complications. Another one is following categories (infections, hardware, organ failure). While some authors report only the mechanical complications that required a procedure [29], someone else report other minor issues such as coccydynia [30].

These different criteria to define complications could explain this wide range of complications rate, that is, because we looked for a reasonable way to classify complications, and we excluded all those events that did not affect the final result. Even a rod breaking if does not affect the correction (because biological fusion is already done) and does not request a new surgery, has not to be considered a complication.

Data from this retrospective study show as the rate of complications in different neuromuscular diseases varies from 10.71 to $50 \%$ (Table 1 ).

Interesting is the comparison among the most known neuromuscular diseases (CP, MD, SMA, Rett). Showing results as percentage of that complication over total adverse events in that group, CP patients were more likely to develop mechanical complications $(23.81 \%, 5$ mechanical complications over 21 total complications in $\mathrm{CP}$ group) and wound infections $(23.81 \%, 5 / 21) ; 35.71 \%(5 / 14)$ of MD patients developed wound infections; SMA patients were more likely to suffer of mechanical $(33.33 \%, 5 / 15)$ and respiratory $(20.00 \%, 3 / 15)$ complications; RS patients had similar prevalence of mechanical and respiratory complication and wound infections $(33.33 \%, 2 / 6)$.

The overall rate of complication was similar in these four groups and it was not statistically significant $(p>0.05)$.

The largest rate of complications was recorded in the PMD group, 6 complications in 12 patients, 2 mechanical complications, 2 wound infections and 2 respiratory complications that seem to be the higher risk group, even if its small size could affect the significance of these data.

Conversely, the smallest complication rate was recorded in the group Others with an overall rate of $10.71 \%$ $(p<0.05)$.

About complications related to hardware, it is pretty evident how the newer Hybrid instrumentation is definitely more affordable that the old Luque instrumentation (that have been used in the first patients, Table 3 ). This has been confirmed by the statistical analysis that shows a $p<0.05$.

Removal of instrumentation has been needed in 12 cases, 9 for infection and 3 due to mechanical issues. In the $50 \%$ of removals had loss of correction: four patients with early infection and two patients with mechanical issues.

In others six cases, five late infections and one broken rod, correction has been maintained at follow-up due to the arthrodesis.

Total failure of treatment has been observed in 17 patients: two deaths, six permanent instrumentation removals with loss of correction, five mechanical breakdowns, four severe permanent outcomes.

Therefore, if complications were observed in $29.73 \%$ of the patients, true failures were $9.19 \%$.

Compared with idiopathic scoliosis, neuromuscular scoliosis patients requiring spine surgery have a higher risk of adverse perioperative complications because of 
underlying comorbidities [31, 32]. Comorbidities commonly associated with neuromuscular scoliosis are decreased pulmonary function, inadequate nutritional status, decreased mobility, and communication and cognitive impairment. Complication rate after surgical correction of neuromuscular scoliosis is variable according to different authors but remains high [31, 33-43]. In these different studies, complication rate ranges from 17 to $74 \%$, Benson et al. [38] reporting the highest rate with 17 complications in 24 patients, predominantly infectious and respiratory problems. Our results are consistent with an overall complication rate of $30 \%$. Curve magnitude and non-ambulatory status have been described as risk factors of major postoperative complications [34].

Among complications, prevalence of wound infections ranges from 8.7 to $20 \%$ [34, 44-46]. Degree of patients' cognitive impairment, malnutrition, respiratory problems, and intraoperative bleeding are associated with an increased infectious rate [45, 47-49]. In our series, a wound infection was diagnosed in $24.3 \%$ of the population.

Respiratory complications are a major concern in these patients, occurring in 23.5 to $57 \%$ of cases [38, 43, 50]. The analysis of our series found respiratory complications in only $13.6 \%$ of the population. This observation may be the consequence of the respiratory preparation patients underwent before surgery (noninvasive ventilation and physiotherapy). It has been previously proved that patients' preoperative general status was correlated to complication rate [29]. Thus, we believe that respiratory preparation is of major importance in these patients' management [51-54].

Digestive complications remain relatively rare in the literature [32, 38, 43]. However, this kind of complications may be serious. In our series, one patient had a peptic ulcer that could turn in perforation and become a serious complication. In the same way, Master et al. [34] reported major gastrointestinal complications with two cast syndrome cases and one case of concomitant gallbladder hydrops and pancreatitis. Risk factors for digestive complications are hypotensive anesthesia [55], intraoperative position, and malnutrition, especially in cast syndrome occurrence [47, 56]. Attention should be given to this patient again in preparation to surgery and post-care, to prevent these apparently minor but potentially major complications.

About hardware related problems in the literature the prevalence ranges from $3.4 \%$ to Mohamad [31] to $21 \%$ of Gau [27], 32\% of Nectoux [43] $44.4 \%$ of Modi [30]. It depends most of the time, as showed in our study, by the type of instrumentation used. Among last 30 years, several different hardware were followed. Different results most of the time reflect different hardware.

We have to mention Reames [39] that carried out a well done large retrospective multicentric study of 19,360 patients with an overall complication rates $10.2 \%$ (1971 patients); 4897 were neuromuscular scoliosis in which the complication rate was $17.9 \%$ (835 complications in 4657 neuromuscular scoliosis). The neuromuscular group included post spinal cord injury and neural tumor that maybe should consider in a different group; conversely syndromic diseases were placed in the group named "Others". Despite we appreciated the paper, maybe groupage is questionable, and it could affect the final result.

Sharma [42] performed an accurate meta-analysis of the past 15 years' literature recording an overall pooled rate of $22.71 \%$ pulmonary complications, $12.51 \%$ of implant related complications and $10.91 \%$ of infections. Implant revision and removal were $7.87 \%$.

This study is in agreement with our beliefs because authors noticed as level of evidence among the literature ranged between $2+$ and $2-$ with a large heterogeneity in methodology and outcome types that could well explain the wide range of outcomes.

\section{Conclusions}

Our study confirms that, as reported in the literature, the surgical treatment in neuromuscular scoliosis is burdened by a large number of complications. Complications were observed in 55 patients out of 185 (29.73\%). The mechanical complications seem to be more frequent in cases operated with Luque instrumentation compared to those made with hybrid instrumentation. However, most of the complications have been addressed and resolved with medical therapy or with use of secondary procedures. Although the amount of complications in the surgery of neuromuscular scoliosis is still remarkable, most of complications can be successfully treated. A standardized preoperative patient evaluation and preparation including respiratory rehabilitation and nutritional care are mandatory prior to surgery. Perioperative management strategy may decrease postoperative complications and increases outcomes. An accurate knowledge of possible complications is mandatory to prepare strategies due to prevent adverse events.

Moreover, the study shows as data analysis is a questioned and significant aspect in research. A difference in definitions could completely change results in good or bad as well as in our same series the adverse events amounted at almost $30 \%$ of cases but complications that due to complete failure would amount at $9.19 \%$ of total patients.

\section{Compliance with ethical standards}

Conflict of interest None. 


\section{References}

1. Sucato DJ (2007) Spine deformity in spinal muscular atrophy. J Bone Jt Surg Am 89-A:148-154

2. Saito N, Ebara S, Ohotsuka K et al (1998) Natural history of scoliosis in spastic cerebral palsy. Lancet 351:1687-1692

3. Harrison DJ, Wepp PJ (1990) Scoliosis in Rett syndrome: natural history and treatment. Brain Dev 12(1):154-156

4. Basset GS, Tolo VT (1990) The incidence and natural history of scoliosis in Rett syndrome. Dev Med Child Neurol 32(11):963-966

5. Robin GC, Brief LP (1971) Scoliosis in childhood muscular dystrophy. J Bone Jt Surg Am 53(3):466-476

6. Rideau Y, Glorion B, Delaubier A et al (1984) The treatment of scoliosis in Duchenne muscular dystrophy. Muscle Nerve 7(4):281-286

7. Yamashita T, Kanaya K, Kawaguchi S et al (2001) Prediction of progression of spinal deformity in Duchenne muscular dystrophy: a preliminary report. Spine (Phila Pa 1976) 26(11):E223-E226

8. Hensinger RN, MacEwen GD (1976) Spinal deformity associated with heritable neurological conditions: spinal muscular atrophy, Friedreich's ataxia, familial dysautonomia, and Charcot-MarieTooth disease. J Bone Jt Surg Am 58:13-24

9. Walker JL, Nelson KR, Stevens DB et al (1994) Spinal deformity in Charcot-Marie-Tooth disease. Spine 19(9):1044-1047

10. Cambridge W, Drennan JC (1987) Scoliosis associated with Duchenne muscular dystrophy. J Pediatr Orthop 7(4):436-440

11. Yokohama C, Hayashi M (1995) The effect of early treatment for children with cerebral palsy. Hattatsu T 27(6):480-486

12. Miller A, Temple T, Miller F (1996) Impact of orthoses on rate of scoliosis progression in children with cerebral palsy. J Pediatr Orthop 16:332-335

13. Heller KD, Forst R, Forst J et al (1997) Scoliosis in Duchenne muscular dystrophy: aspect of orthotic treatment. Prosthet Orthot Int 21(3):202-209

14. Evans GA, Drennan JC, Russman BS (1981) Functional classification and orthopaedic management of spinal muscular atrophy. J Bone Jt Surg Br 63:516-522

15. Granata C, Cervellati S, Ballestrazzi A et al (1993) Spine surgery in spinal muscular atrophy: long-term results. Neuromuscul Disord 3:207-215

16. Piasecki JO, Mahinpour S, Levine DB (1986) Long-term followup of spinal fusion in spinal muscular atrophy. Clin Orthop Relat Res 207:44-54

17. Bentley G, Haddad F, Bull TM et al (2001) The treatment of scoliosis in muscular dystrophy using modified Luque and Harrington-Luque instrumentation. J Bone Jt Surg Br 83:22-28

18. Broom MJ, Banta JV, Renshaw TS (1989) Spinal fusion augmented by Luque-rod segmental instrumentation for neuromuscular scoliosis. J Bone Jt Surg Am 71:32-44

19. Lonstein JE, Akbarnia BA (1983) Operative treatment of spinal deformities in patients with cerebral palsy or mental retardation. An analysis of one hundred and seven cases. J Bone Jt Surg 65-A:43-55

20. Teli MG, Giannella S, Vincitorio F et al (2006) Spinal fusion with Cotrel-Dubousset instrumentation for neuropathic scoliosis in patients with cerebral palsy. Spine 31(14):E441-E447

21. Coe JD, Arlet V, Donaldson W et al (2006) Complications in spinal fusion for adolescent idiopathic scoliosis in the new millennium. A report of the Scoliosis Research Society Morbidity and Mortality Committee. Spine 31(3):345-349

22. Carreon L, Puno R, Lenke L et al (2007) Non-neurologic complications following surgery for adolescent idiopathic scoliosis. J Bone Jt Surg Am 89:2427-2432
23. Rihn JA, Lee JY, Ward WT (2008) Infection after the surgical treatment of adolescent idiopathic scoliosis: evaluation of the diagnosis, treatment, and impact on clinical outcomes. Spine 33(3):289-294

24. Ramo BA, Roberts DW, Tuason D et al (2014) Surgical site infections after posterior spinal fusion for neuromuscular scoliosis: a 30-year experience at a single institution. J Bone Jt Surg Am 96(24):2038-2048

25. Pesenti S, Blondel B, Peltier E et al (2016) Experience in perioperative management of patients undergoing posterior spine fusion for neuromuscular scoliosis. Biomed Res Int 2016:3053056

26. Boachie-Adjej O, Lonstein JE, Winter RB et al (1989) Management of neuromuscular spinal deformities with Luque segmental instrumentation. J Bone Jt Surg Am 71:548-562

27. Gau YL, Lonstein JE, Winter RB et al (1991) Luque-Galveston procedure for correction and stabilization of neuromuscular scoliosis and pelvic obliquity: a review of 68 patients. J Spinal Disord 4:399-410

28. Rampersaud YR, Neary MA, White K (2010) Spine adverse events severity system: content validation and interobserver reliability assessment. Spine (Phila Pa 1976) 35(7):790-795

29. Cervellati S, Bettini N, Moscato M, Gusella A, Dema E, Maresi R (2004) Surgical treatment of spinal deformities in duchenne muscular dystrophy: a long term follow-up study. Eur Spine J 13(5):441-448

30. Modi H, Suh SW, Yang JH et al (2009) Surgical complications in neuromuscular scoliosis operated with posterior-only approach using pedicle screw fixation. Scoliosis 7(4):11

31. Mohamad F, Parent S, Pawelek J et al (2007) Perioperative complications after surgical correction in neuromuscular scoliosis. J Pediatr Orthop 27:392-397

32. Miller NH, Benefield E, Hasting L, Carry P, Pan Z, Erickson MA (2010) Evaluation of high-risk patients undergoing spinal surgery: a matched case series. J Pediatr Orthop 30(5):496-502

33. McDonnell MF, Classman SD, Dimar JRII, Puno RM, Johnson JR (1996) Perioperative complications of anterior procedures on the spine. J Bone Jt Surg Am 78(6):839-847

34. Master DL, Son-Hing JP, Poe-Kochert C, Armstrong DG, Thompson GH (2011) Risk factors for major complications after surgery for neuromuscular scoliosis. Spine (Phila Pa 1976) 36(7):564-571

35. Frischhut B, Sterzinger W, Rachbauer F, Klestil T, Krismer M, Bauer R (1997) Surgical treatment of neuropathic scoliosis: morphologic and functional outcome. Arch Orthop Trauma Surg 116(6-7):367-372

36. Comstock CP, Leac J, Wenger DR (1998) Scoliosis in total-bodyinvolvement cerebral palsy. Analysis of surgical treatment and patient and caregiver satisfaction. Spine (Phila Pa 1976) 23(12):1412-1424

37. Sarwahi V, Sarwark JF, Schafer MF, Backer C, Lee M, King EC, Aminian A, Grayhack JJ (2001) Standards in anterior spine surgery in pediatric patients with neuromuscular scoliosis. J Pediatr Orthop 21(6):756-760

38. Benson ER, Thomson JD, Smith BG, Banta JV (1998) Results and morbidity in a consecutive series of patients undergoing spinal fusion for neuromuscular scoliosis. Spine (Phila Pa 1976) 23(21):2308-2317

39. Reames DL, Smith JS, Fu KM, Polly DW Jr, Ames CP, Berven SH, Perra JH, Glassman SD, McCarthy RE, Knapp RD Jr, Heary R, Shaffrey CI, Scoliosis Research Society Morbidity and Mortality Committee (2011) Complications in the surgical treatment of 19,360 cases of pediatric scoliosis: a review of the scoliosis research society morbidity and mortality database. Spine (Phila Pa 1976) 36(18):1484-1491 
40. Tsirikos AI, Lipton G, Chang W-N, Dabney KW, Miller F (2008) Surgical correction of scoliosis in pediatric patients with cerebral palsy using the unit rod instrumentation. Spine (Phila Pa 1976) 33(10):1133-1140

41. Miladi LT, Ghanem IB, Draoui MM, Zeller RD, Dubousset JF (1997) Iliosacral screw fixation for pelvic obliquity in neuromuscular scoliosis: a long-term follow-up study. Spine (Phila Pa 1976) 22(15):1722-1729

42. Sharma S, Wu C, Andersen T, Wang T, Hansen ES, Bünger CE (2013) Prevalence of complications in neuromuscular scoliosis surgery: a literature meta-analysis from the past 15 years. Eur Spine J 22(6):1230-1249

43. Nectoux E, Giacomelli MC, Karger C, Herbaux B, Clavert JM (2010) Complications of the Luque-Galveston scoliosis correction technique in paediatric cerebral palsy. Orthop Traumatol Surg Res 96(4):354-361

44. Szöke G, Lipton G, Miller F, Dabney K (1998) Wound infection after spinal fusion in children with cerebral palsy. J Pediatr Orthop 18(6):727-733

45. Sponseller PD, LaPorte DM, Hungerford MW, Eck K, Bridwell KH, Lenke LG (2000) Deep wound infections after neuromuscular scoliosis surgery: a multicenter study of risk factors and treatment outcomes. Spine (Phila Pa 1976) 25(19):2461-2466

46. Theiss SM, Lonstein JE, Winter RB (1996) Wound infections in reconstructive spine surgery. Orthop Clin North Am 27(1): 105-110

47. Jevsevar DS, Karlin LI (1993) The relationship between preoperative nutritional status and complications after an operation for scoliosis in patients who have cerebral palsy. J Bone Jt Surg Am 75(6):880-884
48. Klein JD, Garfin SR (1996) Nutritional status in the patient with spinal infection. Orthop Clin North Am 27(1):33-36

49. Triulzi DJ, Vanek K, Ryan DH, Blumberg N (1992) A clinical and immunologic study of blood transfusion and postoperative bacterial infection in spinal surgery. Transfusion 32(6):517-524

50. Lascombes P, Fabre B, Bresler F, Schweitzer F, Prevot J (1989) Surgical treatment of spinal deformity due to cerebral motor disorders using a Luque type appliance. Chir Pediatr 30(6):271-276

51. Almenrader N, Patel D (2006) Spinal fusion surgery in children with non-idiopathic scoliosis: is there a need for routine postoperative ventilation? Br J Anaesth 97(6):851-857

52. Gill I, Eagle M, Mehta JS, Gibson MJ, Bushby K, Bullock R (2006) Correction of neuromuscular scoliosis in patients with preexisting respiratory failure. Spine (Phila $\mathrm{Pa}$ 1976) 31(21):2478-2483

53. Yuan N, Skaggs DL, Dorey F, Keens TG (2005) Preoperative predictors of prolonged postoperative mechanical ventilation in children following scoliosis repair. Pediatr Pulmonol 40(5):414-419

54. Padman R, McNamara R (1990) Postoperative pulmonary complications in children with neuromuscular scoliosis who underwent posterior spinal fusion. Del Med J 62(5):999-1003

55. Bell DF, Moseley CF, Koreska J (1989) Unit rod segmental spinal instrumentation in the management of patients with progressive neuromuscular spinal deformity. Spine (Phila Pa 1976) 14(12):1301-1307

56. Mandelbaum BR, Tolo VT, McAfee PC, Burest P (1988) Nutritional deficiencies after staged anterior and posterior spinal reconstructive surgery. Clin Orthop Relat Res 234:5-11 